\title{
We Are Needed More Than Ever: \\ Cultural Heritage, Libraries, and Archives
}

\author{
Anita Eichinger and Katharina Prager
}

\begin{abstract}
Libraries and archives as institutions of cultural heritage have a long history of and great expertise in collecting, securing, handling, and contextualizing masses of material and data. In the context of digital humanism, these institutions might become essential as a model as well as a field of experimentation. Questioning their own role as gatekeepers and curators, the digital transformation offers them the chance to open up - through both participatory initiatives and inclusive collecting. At the same time, however, it is a matter of preserving the library and archive as a place of encounter and personal dialogue in a human and humanist tradition.
\end{abstract}

The Corona crisis has given digitization a huge boost in many areas, which need to be developed further in a strategic and co-designing way - without subordinating ourselves to technologies but shaping them. The City of Vienna currently encourages and orchestrates innovative ideas, collaborative action, and social engagement in this field in its framework initiative "digital humanism." With Anita Eichinger, the Vienna City Library was involved from the very beginning and took on the mentorship of the working group on arts and culture. ${ }^{1}$

The Vienna City Library, ${ }^{2}$ often described as "memory of the city," has developed over the last 170 years from an inconspicuous administrative library (founded in 1856) into a representative city library, a municipal cultural institution, and one of the most important scholarly archives with a special focus on Vienna. It holds around 6,500,000 volumes of books on Vienna (Viennensia and Austriaca); 1600 bequests of important inhabitants of the city (such as Franz Grillparzer, Marie von EbnerEschenbach, Franz Schubert, Johann Strauss, Karl Kraus, or Friederike Mayröcker),

\footnotetext{
${ }^{1}$ It consists of Gerald Bast, Daniel Löcker, and Carmen Aberer (MA 7) and Irina Nalis, Elfriede Penz, Erich Prem, Eveline Wandl-Vogt, and Hannes Werthner as well as Anita Eichinger and Katharina Prager (MA 9) and formulated a position paper on "Digital Humanism and Arts/Culture."

${ }^{2}$ See https://www.wienbibliothek.at/english and https://www.digital.wienbibliothek.at/.
}

\footnotetext{
A. Eichinger $\cdot$ K. Prager $(\bowtie)$

Vienna City Library, Vienna, Austria

e-mail: anita.eichinger@wienbibliothek.at; katharina.prager@wienbibliothek.at
} 
some of them part of the UNESCO Memory of the World; and one of the world's largest poster collection. Apart from these central holdings, it also collects newspaper clippings, historical photographs, sermons, leaflets, travel reports, cookbooks, and much more. Over the past decade, there has been a strong focus on retrodigitization - and while digital accessibility of materials remains a priority, the library is concentrating on research, innovation, and digital humanism in the years to come.

Although the Vienna Library is not an art and cultural institution per se, it is an important interface in the cultural field, with expertise in safeguarding and mediating cultural assets.

In our current global situation - where we are dealing with the monopolization of the web, the spread of extremist attitudes, anti-factualism, filter bubbles and echo chambers, the loss of privacy, and many other problems - the importance of archives and libraries cannot be overstated. Historian Jill Lepore most recently pointed out these connections and the history of evidence, proof, and knowledge in her podcast "The Last Archive."3

Keeping track, filing, and cataloguing are important tools in bibliographic control. However, it is also essential to understand creativity, imagination, social and critical competence, change of perspective, inclusion, diversity, and much more as central contents of cultural and artistic activity. The abovementioned working group on arts and culture made it clear in its position paper that art, culture, and the competences of the creative must help shape digital humanism as fundamental factors - a matter that has been obvious to technology monopolies, for example, for a long time already.

It can be argued that libraries and archives also have some experience in combining creativity with order or chaos with systematics and adapting their practices to the logics of human art and knowledge production over centuries.

The Vienna City Library keeps the historical records of a city renowned worldwide as a city of culture and - in the last decades - also as a center of social, scientific, and technological innovation. In this respect, it can also refer to its legendary intellectual history: Before and after World War I, fin-de-siècle Vienna and Red Vienna achieved international significance in the cultural and social sphere. After the end of the Austrian monarchy in 1918, the city's leaders, together with its intellectuals, boldly "imagined a new society that would be economically just, scientifically rigorous, and radically democratic. 'Red Vienna' undertook experiments in public housing, welfare, and education while maintaining a world-class presence in science, music, literature, theater, and other fields of cultural production" (McFarland et al. 2020). The roots of the ideas that came to life in the first Austrian republic were often already established in fin-de-siècle Vienna. Mostly, they were a reaction to profound societal, technological, and medial changes. The fields of medicine, economics, art, and philosophy reacted to this turmoil and sought for new ways of living - Freud's psychoanalysis, the philosophers of the Vienna Circle,

\footnotetext{
${ }^{3}$ See https://www.thelastarchive.com/.
} 
or the epochal innovations in music driven by Schönberg and the Vienna School are still known to this day. Today, we are in a similar situation of upheaval. Digital humanism aims to encourage people to think and to shape the digital future in a new way. So much for the broader context - but what do digital transformation and digital humanism involve in the context of the Vienna City Library, whose duty it is to preserve the cultural heritage of the city - and also for libraries and archives in general?

Digital humanism calls for a "third way" of digitization. This means that there must be an alternative way to Silicon Valley and China, a way without aiming for profit or authoritarianism, but for the benefit of humanity. In 2004, the Google Books project started. Google worked together with libraries and publishers around the world to preserve books and to make the information accessible to people worldwide. Prominent and huge university libraries have cooperated with Google since that time. Jean-Noel Jeanneney, head of Bibliothèque nationale de France from 2002 to 2007, cautioned against Google and "Americanization" and argued for a European digital library (Jeanneney 2006). Although Jeanneney was polemic in his book, there is one important conclusion to be drawn: Cultural heritage is a public good, therefore, it should remain public property. Digitizing books and other sources in libraries and making them accessible to the public and the scientific world must be the responsibility of public non-commercial institutions. Parallel to Google archives, libraries and museums around the world also started massive programs not only to digitize their collections but also to contextualize them and, therefore, gain additional values and new insights (e.g., citizen science projects, digital history platforms, digital humanities projects). Libraries are at a turning point. They have good prerequisites and qualifications, but they need to change their perspective on what they have been doing for thousands of years. The Vienna City Library takes digital humanism as a chance to reposition itself. In the following, we outline four important new tasks as part of its strategy to answer the challenges of the digital age.

\section{Self/Education}

This term is meant to combine two aspects, namely, the mission to educate a wider public as well as oneself as part of a library. First, it should be a central task of libraries to systematically counteract to the digital gap and to train critical, responsible users, as well as designers of our digital life, together. Archives and libraries have habitually and for centuries dealt with masses of data, disorder, gaps, and search and selection processes. The systematic, precise handling of data is one of their core competences, and they should learn to impart this knowledge, which is so often a desideratum elsewhere, to a wider audience. In the spirit of digital humanism, this should also increasingly involve marginalized and disadvantaged groups to whom the culturally transmitted knowledge of a community has often not been easily accessible for various reasons (language, educational background, etc.). The role of the librarians and archivists is changing from reclusive gatekeepers of hidden 
treasures to guides that help users navigate contradictory data systems. In this context, it is necessary for librarians to acquire skills of the future and to try out new cultural techniques. These include, among others, dealing with ambiguity and uncertainty; imagination and association; intuition; thinking in terms of alternatives; establishing unconventional contexts; challenging the status quo; and changing perspectives.

\section{Participatory Turn}

To get this self/education started and to initiate a "participatory turn" in archives and libraries, the Vienna City Library aims at launching a pilot project in the realm of digital humanism. Under the working title "WE make history," the first step will be to enter cooperations with peer institutions documenting the city's history and to link and visualize all digitized and digitizable sources. In a second essential step, it will then be a matter of inquiring who remains invisible and why. As a result, it is intended to make it possible to enrich, supplement, and retell the city's multiperspective history, in order to offer groups that have been excluded from the creation of cultural heritage opportunities to contribute their stories and their versions of history. For instance, in the historical address books from 1859 to 1942 , only the heads of the households were listed, and they were mostly male. Combining layers of resources and research, we will not only make all the other persons especially the female half - visible but also take a step further when we ask the Viennese public to enrich these layers of date with life stories, photographs, documents, or other sources. This model project will not only lead to a rethinking of how cultural heritage is conveyed - it will also help to rethink another important area namely, the question of what a library collects and how.

\section{Inclusive Collections}

Collections in archives, museums, and libraries - this is frequently stated - are hardly neutral nor objective storehouses, but reflect power relations. The Vienna Library was no exception when it collected the written material published in Vienna over the last 170 years, as well as the papers of famous authors, musicians, and cultural figures $-76 \%$ of them of male gender. Digital collecting often appears to be the solution for challenging tradition, opening up, and expanding centuries-old structures, but experimenting with digital collection methods in the context of 9/11, Hurricane Katrina, and most recently COVID-19 has shown that it poses new difficulties and opens up other gaps (Rivard 2014). Digital humanism will be a central starting point for critically reflecting on the interplay between technology and identity politics and collecting material in a correspondingly different way. Inclusive collections are, of course, intrinsically linked to a new self-image of 
librarians and archivists - from "guardians of the past" to actors who are concerned with the present, the future, and the construction of social memory (see Self) Education). Secondly, radical repositioning needs the support and participation of a broad community (see Participatory Turn). Altogether, it might be useful to remember that the Vienna City Library always took curatorial liberties when establishing its special collections. It is important to be aware that changes take time and can only be achieved one step after another, project by project.

\section{Remaining a Place for Personal Encounters}

While navigating through these uncertain times of digital transformation in the spirit of digital humanism by self/education, fostering participation, and reframing our collections, it is helpful to keep our feet grounded and remain physically in place. The closure of the archives and libraries, due to the COVID-19 restrictions, did not only lead to debates about the value of archival research but also caused longing for the special atmosphere of these places. In this context, the reading room is not just an arbitrary workplace - although these, too, were nostalgically transfigured in the lockdown - but a special place of exchange that does not only establish the connection between the material and the researcher but also between the archive and the researcher, between the researchers themselves, and, ultimately, between the current collective issues and the collective memory.

The fundamental question is what will remain of archives and libraries, once it has actually been possible to make cultural heritage digitally and barrier-free accessible to all. Will they dissolve as locations or can they gain new significance as venues for analogue debate and human encounters - and if so, how? This field of tension is opening up by digitization, but digital humanism at least hints at answers as to why spaces of human encounters will remain essential - and the experience of a pandemic confirms this.

\section{Conclusions}

Libraries, archives, and our overall attitude toward our cultural heritage are at a crucial turning point in times of digital transformation.

On the one hand, the more digital our lives become, the more we need places like libraries to discuss, interact, and invent new innovative solutions together. On the other hand, the profession of the librarian is often perceived as declining and compared to a soon extinct species. The contrary is the case. Without librarians, we would give our cultural heritage and, therefore, our cultural identity out of our hands. The question of what to collect in the future and how to preserve and protect the digital heritage can only be discussed in participatory exchange and cooperation of librarians with (citizen) scientists and - last but not least - computer scientists. In 
this context, librarians need IT experts to understand which spaces they are opening and closing in the digital realm, how they can position themselves meaningfully at the interfaces, and where data is secure. But IT also needs librarians more than ever to recognize that key practices for dealing with cultural heritage are already in place and that in many cases they can be transformed into the digital realm. The most crucial thing is to realize that all the challenges ahead can only be met through multidisciplinary exchange and mutual understanding.

\section{References}

Jeanneney, Jean-Noel (2006) Googles Herausforderung. Für eine europäische Bibliothek. Berlin: Wagenbach

McFarland, R. Spitaler, G. and Zechner, I. (ed.) The Red Vienna Sourcebook. London: Camden House 2020.

Rivard, C. (2014) Archiving Disaster and National Identity in the Digital Realm: The September 11 Digital Archive and the Hurricane Digital Memory Bank, in: Rak, J. and Poletti, A. (ed.) Identity Technologies: Producing Online Selves. Wisconsin: University of Wisconsin Press, pp. 132-143.

Open Access This chapter is licensed under the terms of the Creative Commons Attribution 4.0 International License (http://creativecommons.org/licenses/by/4.0/), which permits use, sharing, adaptation, distribution and reproduction in any medium or format, as long as you give appropriate credit to the original author(s) and the source, provide a link to the Creative Commons license and indicate if changes were made.

The images or other third party material in this chapter are included in the chapter's Creative Commons license, unless indicated otherwise in a credit line to the material. If material is not included in the chapter's Creative Commons license and your intended use is not permitted by statutory regulation or exceeds the permitted use, you will need to obtain permission directly from the copyright holder.

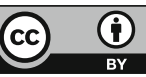

